adulthood and another group who progress to the use of illicit drugs. The characteristics of this minority of young adults who have progressed in their addiction careers will be established only by a rigorous follow up study of a representative sample of solvent misusers, and we shall report on the results of our own follow up study in due course.

\section{References}

1 Thorley A. Medical responses to problem drinking Medicine 1980;35 (3rd series): $1816-22$
2 Plant MA, Peck DF, Stuart R. The correlates of serious alcohol related consequences and illicit drug use amongst a cohort of Scottish teenagers. Brf Addict $1984 ; 79: 197-200$

4 Tyne and Wear Count. Daily Mail 1982; Jan. extent of solvent abuse. Tyne and Wear County Council, 1983.

Masterton G. Management of solvent abuse. F Adolesc 1979;2:65-75.

6 Skuse D, Burrell S. A review of solvent abusers and their management by a child psychiatric outpatient service. Hum Toxicol 1982;3:321-9.

Rubin T, Babbs J. The glue sniffer. Federal Probation 1970;34:23-8.

Parkes CM. Bereavement and mental illness. A classification of bereavement reac-

1983;28:72-6.

Watson IM. Solvent abuse by children and young adults-a review. $\mathrm{Br} \mathcal{f}$ Addict $1980 ; 75: 27-36$.

(Accepted 8 October 1984)

\title{
Moderate potassium chloride supplementation in essential hypertension: is it additive to moderate sodium restriction?
}

\author{
STEPHEN J SMITH, NIRMALA D MARKANDU, GIUSEPPE A SAGNELLA, \\ GRAHAM A MACGREGOR
}

\begin{abstract}
Twenty patients with mild or moderate essential hypertension and not receiving any drug treatment, who had been moderately restricting their sodium intake to around $70 \mathrm{mmol}(\mathrm{mEq})$ a day for at least one month and whose mean blood pressure was then $163 / 103 \mathrm{~mm} \mathrm{Hg}$, were entered into a double blind, randomised crossover study to compare one month's treatment with slow release potassium chloride tablets $(64 \mathrm{mmol}$ potassium chloride a day) with one month's treatment with a matching placebo. Mean (SEM) urinary sodium excretion on entry to the study was $68(6.8) \mathrm{mmol} / 24 \mathrm{~h}$. Mean urinary potassium excretion increased from $67(6.9)$ $\mathrm{mmol}(\mathrm{mEq}) / 24 \mathrm{~h}$ with placebo to $117(4.6) \mathrm{mmol} / 24 \mathrm{~h}$ with potassium chloride. Supine and standing systolic and diastolic blood pressures did not change significantly with potassium chloride supplementation when compared with pressures while receiving placebo or before randomisation.
\end{abstract}

In patients who are able moderately to restrict their sodium intake doubling potassium as a chloride salt has little or no effect on blood pressure.

\section{Introduction}

Reducing sodium intake from the high levels currently consumed in the West $(150-250 \mathrm{mmol}(\mathrm{mEq}) /$ day $)$ to around $60-100 \mathrm{mmol} /$ day causes a fall in blood pressure in patients with sustained essential hypertension..$^{1-3}$ There is some evidence that doubling potassium intake, using potassium chloride, from 60 to 120

Blood Pressure Unit, Department of Medicine, Charing Cross Hospital Medical School, London W6 8RF

STEPHEN J SMITH, BSC, MRCP, honorary senior registrar and British Heart Foundation junior research fellow

NIRMALA D MARKANDU, SRN, research assistan

GIUSEPPE A SAGNELLA, PHD, senior biochemist

GRAHAM A MACGREGOR, MA, FRCP, Wellcome Trust senior lecturer

Correspondence and requests for reprints to: Dr S J Smith. $\mathrm{mmol} /$ day also lowers blood pressure when patients are receiving a high sodium intake-that is, more than $150 \mathrm{mmol} /$ day. ${ }^{45}$ Studies in stock and genetically hypertensive rats ${ }^{6-8}$ and in hypertensive $\operatorname{man}^{4}{ }^{5}$ have suggested that the effect of potassium chloride supplementation on blood pressure is more effective the higher the intake of sodium. No evidence exists concerning the effect of potassium chloride supplementation in patients with essential hypertension who are already moderately restricting their sodium intake to around $70 \mathrm{mmol} / \mathrm{day}$. We therefore conducted a double blind, randomised crossover study of one month's treatment with slow release potassium chloride tablets, $64 \mathrm{mmol}$ potassium chloride a day, or matching placebo tablets in patients who were already restricting their sodium intake to roughly $70 \mathrm{mmol}$ a day.

\section{Patients and methods}

Patients referred by local general practitioners to this unit were included in the study if after two months' observation without treatment their supine diastolic pressure was between 90 and $119 \mathrm{~mm}$ $\mathrm{Hg}$ and no underlying cause for their high blood pressure had been found. If patients were already receiving drug treatment it was stopped at least two months before the start of the study. Patients with renal failure, ischaemic heart disease, or cerebrovascular disease and those taking the oral contraceptive pill or any other drug were excluded from the study. Twenty two patients were considered. One was excluded before the study because he was not willing to restrict his sodium intake. Another was excluded during the study as he was not able to tolerate the potassium chloride tablets. Twenty patients therefore completed the study. There were $11 \mathrm{men}$ and nine women, of whom 18 were white and two black; mean (SEM) age was 53 (3) years (range 30-66).

During a run in period of observation lasting two months all patients were seen fortnightly in the unit for measurement of blood pressure so that they were well used to having their blood pressure measured under standard conditions. After this two month run in period, in which they did not receive any drug treatment, all patients were taught how to restrict their sodium intake moderately to around $70 \mathrm{mmol}$ a day by not adding salt to their food and avoiding foods with a high sodium content. Six of the 20 patients included in the study were already restricting their sodium intake to around this amount.

During an initial month of moderate sodium restriction alone patients were seen every two weeks. They were then all entered into a double blind, randomised, crossover study comparing one month's 
treatment with potassium chloride $64 \mathrm{mmol} /$ day (Slow-K (Ciba) eight tablets a day) with one month's treatment with eight identical placebo tablets (Ciba) a day while continuing to restrict their sodium intake moderately. Nine patients were given potassium chloride first and 11 placebo. The average blood pressure before randomisation was $163 / 103 \mathrm{~mm} \mathrm{Hg}$ (range: systolic $147-206 \mathrm{~mm} \mathrm{Hg}$; diastolic 92-123 $\mathrm{mm} \mathrm{Hg}$ ).

During the study patients were seen at the end of each month of treatment. Each patient was seen on the same day of the week at the same time of day by the same person in the same room. Blood pressure was measured in the same arm with semiautomatic ultrasound $(p<0.001)$. There was no significant difference between urinary potassium excretion on entry to the study and while taking placebo. All patients showed an increase in urinary potassium excretion when the fourth week of placebo was compared with the fourth week of potassium supplementation (fig 1). Urinary sodium excretion on entry to the study was $68(6.8) \mathrm{mmol} / 24 \mathrm{~h}$, after one month of treatment with potassium chloride $80(6 \cdot 8) \mathrm{mmol} / 24 \mathrm{~h}$, and after one month of receiving placebo $73(7 \cdot 6) \mathrm{mmol} / 24 \mathrm{~h}$ (table). Urinary creatinine excretion showed no significant change during the study (table).

With potassium supplementation there were no significant changes

Mean (SEM) clinical findings in 20 patients with hypertension receiving a moderately restricted sodium intake, before and after four weeks of treatment with potassium chloride or placebo

\begin{tabular}{|c|c|c|c|}
\hline & $\begin{array}{l}\text { Fourth week of } \\
\text { restricted sodium } \\
\text { intake alone }\end{array}$ & Potassium chloride & Placebo \\
\hline $\begin{array}{l}\text { Supine blood pressure }(\mathrm{mm} \mathrm{Hg}) \\
\text { Standing blood pressure }(\mathrm{mm} \mathrm{Hg}) \\
\text { Supine heart rate }(\text { beats } / \mathrm{min}) \\
\text { Weight }(\mathrm{kg}) \\
\text { Urinary sodium }(\mathrm{mmol} / 24 \mathrm{~h}) \\
\text { Urinary potassium }(\mathrm{mmol} / 24 \mathrm{~h}) \\
\text { Urinary creatinine }(\mu \mathrm{mol} / 24 \mathrm{~h}) \\
\text { Plasma renin activity }(\mathrm{nmol} / 1 / \mathrm{h}) \\
\text { Plasma aldosterone }(\mathrm{pmol} / \mathrm{l}) \\
\text { Plasma potassium }(\mathrm{mmol} / \mathrm{l}) \\
\text { Blood urea }(\mathrm{mmol} / \mathrm{m}) \\
\text { Plasma creatinine }(\mu \mathrm{mol} / \mathrm{l})\end{array}$ & $\begin{array}{c}163 / 103(4 \cdot 3 / 2 \cdot 2) \\
160 / 110(4 \cdot 8 / 2 \cdot 3) \\
75(3 \cdot 6) \\
72 \cdot 1(2 \cdot 4) \\
68(6 \cdot 8) \\
72(4 \cdot 8) \\
12 \cdot 1(0 \cdot 8) \\
0 \cdot 92(0 \cdot 11) \\
357(46) \\
4 \cdot 0(0 \cdot 1) \\
5 \cdot 0(0 \cdot 3) \\
91(4 \cdot 0)\end{array}$ & $\begin{array}{c}160 / 103(3 \cdot 6 / 2 \cdot 4) \\
160 / 110(4 \cdot 5 / 2 \cdot 2) \\
77(2 \cdot 7) \\
72 \cdot 1(2 \cdot 1) \\
80(6 \cdot 8) \\
117(4 \cdot 6)^{*} \\
11 \cdot 6(0 \cdot 7) \\
0 \cdot 92(0 \cdot 11) \\
448(64) \\
4 \cdot 1(0 \cdot 1) \\
5 \cdot 2(0 \cdot 3) \\
89(3 \cdot 8)\end{array}$ & $\begin{array}{c}162 / 103(3 \cdot 4 / 2 \cdot 0) \\
160 / 111(3 \cdot 5 / 1 \cdot 9) \\
78(3 \cdot 4) \\
72 \cdot 0(2 \cdot 2) \\
73(7 \cdot 6) \\
67(6 \cdot 9) \\
11 \cdot 8(0 \cdot 7) \\
1(0 \cdot 15) \\
385(54) \\
3 \cdot 9(0 \cdot 1) \\
4 \cdot 7(0 \cdot 3) \\
91(3 \cdot 2)\end{array}$ \\
\hline
\end{tabular}

* Compared with placebo: $\mathrm{p}<0.0001$

$t_{n}=19$.

Conversion: SI to traditional units-Sodium: $1 \mathrm{mmol}=1 \mathrm{mEq}$. Potassium: $1 \mathrm{mmol}=1 \mathrm{mEq}$. Creatinine: $1 \mu \mathrm{mol} \approx 113 \mu \mathrm{g}$. Plasma renin activity: $1 \mathrm{nmol} / 1 / \mathrm{h} \approx 1 \cdot 3 \mathrm{ng} / \mathrm{ml} / \mathrm{h}$. Aldosterone: $1 \mathrm{pmol} / 1 \approx$ $36 \mathrm{pg} / 100 \mathrm{ml}$. Urea: $1 \mathrm{mmol} / \mathrm{l} \approx 6 \mathrm{mg} / 100 \mathrm{ml}$

sphygmomanometers (Arteriosonde) ${ }^{9}$ with attached recorders. The measurements were therefore free from observer bias. Supine and standing blood pressures were the means of five readings taken every one to two minutes. Pulse rate was measured with a pulse monitor (Cambridge 3048). During sodium restriction and at the end of the fourth and eighth weeks of the crossover study two 24 hour urine samples were collected and blood was also taken for measurement of urea, electrolyte, creatinine, and aldosterone concentrations and plasma renin activity. Urinary excretions of sodium, potassium, and creatinine for each occasion were taken as the mean of two consecutive 24 hour urine samples. All blood samples were taken without stasis after the patient had been sitting upright for 10 minutes, some time between 1000 and 1200. Plasma renin activity and aldosterone concentration were measured by radioimmunoassay. ${ }^{1011}$

Written consent was obtained from each patient. Mean arterial pressure was calculated by adding one third of the pulse pressure to the diastolic pressure. All results are reported as the mean (SEM). Based on blood pressure while taking potassium chloride or placebo, the study had a $95 \%$ chance of picking up a fall of $6 / 4 \mathrm{~mm} \mathrm{Hg}$ in blood pressure.

Statistical analysis was performed using the University of London's computer and the north western universities' statistical package for social sciences.

\section{Results}

During the two month randomised crossover study there were no significant changes in supine systolic or diastolic pressure or standing systolic or diastolic pressure with potassium chloride supplementation as compared with placebo or sodium restriction alone (table). In the 14 of the 20 patients who restricted their sodium intake for the first time during the month before the study there was a significant fall in supine systolic pressure $(p<0.02)$ and a non-significant fall in diastolic pressure with moderate sodium restriction (blood pressure: before treatment $=173 / 105(3.8 / 3.0) \mathrm{mm} \mathrm{Hg}$; in the fourth week of sodium restriction $=163 / 101(4 \cdot 1 / 2 \cdot 4) \mathrm{mm} \mathrm{Hg} ; \mathrm{n}=14)$. Blood pressure fell after four weeks of sodium restriction in these patients by a mean of $4.8^{\circ}(\mathrm{p}<0.02)$. In these 14 patients 24 hour urinary excretion of sodium fell significantly from $156 \mathrm{mmol} / 24 \mathrm{~h}$ during normal sodium intake to $70 \mathrm{mmol} / 24 \mathrm{~h}$ when restricting sodium intake $(\mathrm{p}<0.001)$.

Mean urinary potassium excretion increased from $72(4.8) \mathrm{mmol} /$ $24 \mathrm{~h}$ before randomisation to $117(4 \cdot 6) \mathrm{mmol} / 24 \mathrm{~h}$ with potassium chloride supplementation and was $67(6.9) \mathrm{mmol} / 24 \mathrm{~h}$ while receiving placebo. There was therefore a mean increase of $50 \mathrm{mmol} / 24 \mathrm{~h}$ with potassium chloride supplementation compared with placebo

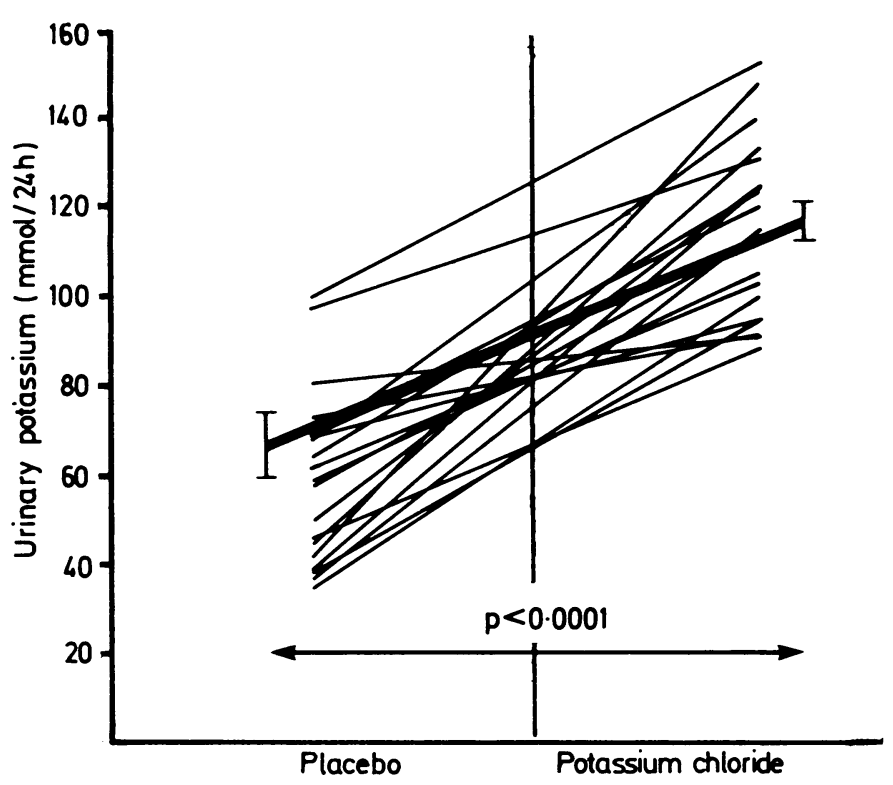

FIG 1-Individual and mean changes in urinary potassium excretion between fourth week of placebo and fourth week of potassium chloride treatment $(n=19)$.

Conversion: SI to traditional units-Potassium: $1 \mathrm{mmol} / 24 \mathrm{~h} \approx 1 \mathrm{mEq} / 24 \mathrm{~h}$.

in plasma renin activity (table). There was an increase in plasma aldosterone concentration, but this was not significant (table).

Plasma potassium concentration increased by $0.2 \mathrm{mmol}$ between the fourth week of treatment with potassium chloride and the fourth week of placebo, but this increase was not significant (table). There were no significant changes in blood urea or plasma creatinine concentrations or heart rate during the study.

Comparing the mean arterial pressure in the fourth week of treatment with placebo and the fourth week of treatment with potassium chloride, 10 patients showed a fall in mean arterial pressure and 10 showed a rise (fig 2). There was no obvious difference between these two groups of patients when other variables were considered. Looking at the changes in other measurements, there did not appear to be any explanation for the difference in response, which was 
probably due to random variation. There was no correlation between the change in blood pressure between the fourth week of potassium chloride treatment and the change in urinary potassium at these times. Potassium supplementation was not continued after the end of the trial.

\section{Discussion}

Our lindings showed that in patients with mild to moderate essential hypertension who were already moderately restricting their sodium intake to around $70 \mathrm{mmol} /$ day doubling potassium intake as a chloride salt ( $64 \mathrm{mmol}$ potassium chloride a day) did not cause any further significant fall in blood pressure. Compliance with sodium restriction and potassium chloride supplementation was good as shown by 24 hour urinary excretions of sodium and potassium. The finding that potassium chloride

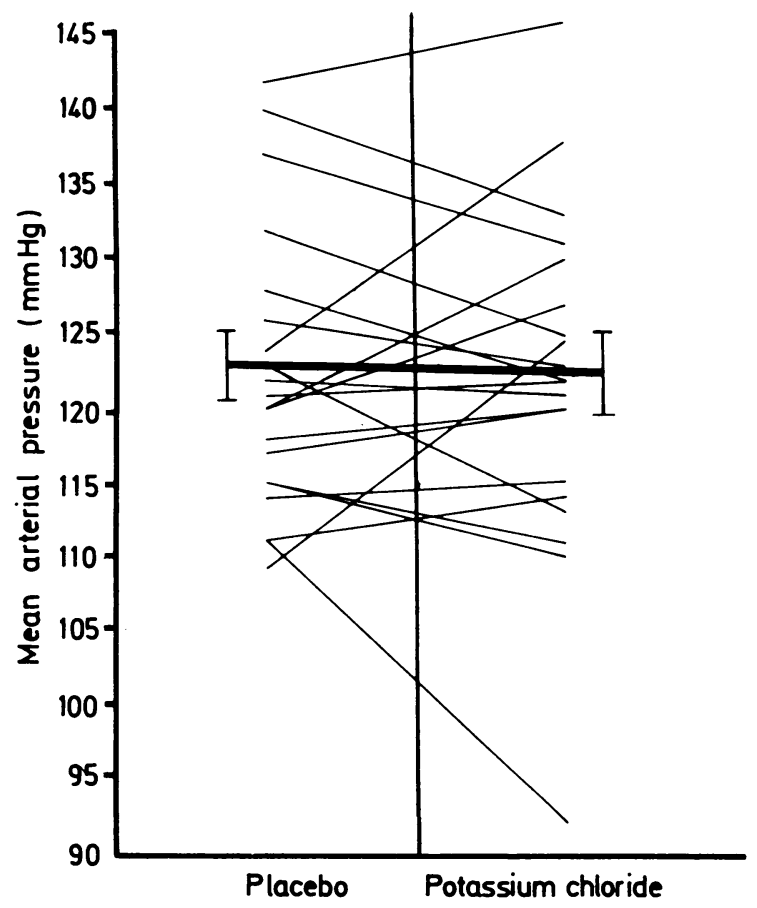

FIG 2-Individual and mean changes in mean arterial pressure between fourth week of placebo and fourth week of potassium chloride treatment.

supplementation becomes less effective as sodium intake is decreased fits with previous findings in animals ${ }^{6-8}$ and also with the limited studies that have been done in patients with essential hypertension. In an identical study that we conducted in patients with essential hypertension but whose sodium intake was not restricted (mean urinary sodium excretion 152 $\mathrm{mmol} / 24 \mathrm{~h}$ ) mean arterial pressure fell by $4 \%,{ }^{5}$ whereas in a study in Japan of patients with a higher sodium intake $(260$ mmol a day) a similar increase in potassium chloride intake reduced blood pressure by $10 \%{ }^{4}$ Epidemiological evidence would suggest that, in addition to sodium intake, potassium intake is also important in determining blood pressure in the whole community. ${ }^{12}{ }^{13}$ It is not clear from this evidence whether potassium intake is more important in determining blood pressure in communities with a high sodium intake or in those with a low sodium intake.

Several mechanisms have been postulated whereby potassium chloride supplementation may lower blood pressure. With a sodium intake of $150 \mathrm{mmol}$ a day potassium chloride causes natriuresis. ${ }^{14}$ At the same time, potassium chloride inhibits renin release ${ }^{15}$ so that the expected rise in renin release, and thereby angiotensin II, does not occur with the sodium loss; this could be one mechanism whereby blood pressure falls. ${ }^{14}$ The lack of effect of potassium chloride on blood pressure when sodium intake is restricted could be due to potassium chloride having either less of a natriuretic effect or less effect on renin secretion.

Our results suggest that, if patients are prepared to restrict sodium intake to around $70 \mathrm{mmol} / \mathrm{day}$, there is little point in increasing potassium chloride intake. Our experience in patients with high blood pressure is that it is relatively easy for them to restrict sodium intake to the sort of levels achieved in this study. Many of our patients have been moderately restricting their sodium intake $(60-80 \mathrm{mmol} /$ day $)$ for over two years and have stuck to the diet without problems. Indeed, most of the patients prefer their present diet to their previous one and now find high salt foods unpleasant. We previously showed that in patients with high blood pressure this reduction in sodium intake has the effect of lowering blood pressure. ${ }^{3}$ Others have shown that this degree of sodium restriction is also additive to drugs that lower blood pressure. ${ }^{21617}$ The effect of sodium restriction on blood pressure is greater the higher the blood pressure before treatment. ${ }^{3}$ Not surprisingly, therefore, studies in which patients had blood pressure that was normal or just on the limit of normal ${ }^{18} 19$ have shown a less consistent fall in blood pressure with sodium restriction.

A few patients are not able to restrict sodium intake, and in these potassium supplementation may lower blood pressure. Increasing potassium intake by the amount $(64 \mathrm{mmol} /$ day) that we used in this and our previous study without potassium tablets or elixir is not nearly as easy as reducing sodium intake. In a study of normotensive subjects using a $97 \%$ potassium chloride based salt substitute (No Salt; Revlon) for two weeks the subjects achieved a $30-40 \mathrm{mmol}$ increase in potassium excretion at the end of two weeks. ${ }^{20}$ In longer term studies, however, in patients with essential hypertension some patients were not able to tolerate the salt substitute and found its bitter aftertaste unpleasant. In those patients who were able to take it urinary potassium excretion was increased by only 20 to 30 $\mathrm{mmol} /$ day.

All the studies in man showing that potassium lowers blood pressure have used potassium chloride. Chloride ions themselves have been shown to increase blood pressure in uninephrectomised hypertensive rats treated with desoxycorticosterone acetate. ${ }^{21}$ Chloride ions have also been shown directly to inhibit renin release in man. ${ }^{22}$ Clearly more consideration should be given to the role of chloride ions in the regulation of extracellular volume, and therefore blood pressure, and no definite conclusions can be drawn from our studies as to the effect on blood pressure of increasing intake of potassium as a nonchloride salt-that is, by increasing fruit and vegetable intake. Increasing dietary potassium intake as a non-chloride salt may possibly lower blood pressure when sodium intake is restricted. Even if it does not, such an increase in consumption of fruit and vegetables would help compliance with moderate sodium restriction and might have other advantages; a higher fibre and lower saturated fat content of the diet have both been claimed to lower blood pressure ${ }^{23}{ }^{24}$ independent of a reduction in sodium intake.

\section{References}

1 Morgan T, Gillies A, Morgan G, Adam W, Wilson M, Carney S. Hypertension treated by salt restriction. Lancet $1978 ; \mathrm{i}: 227-30$.

2 Parijs J, Jcossens JV, Van der Linden L, Vergregen G, Amery AKPC. Moderate sodium restriction and diuretics in the treatment of hypertension. Am Heart $1973 ; 85: 22-34$

3 MacGregor GA. Markandu ND, Best FE, et al. A double blind randomised crossover trial of moderate sodium restriction in essential hypertension.

4 Iimura O, Kijima T, Kikuchi K, et al. Studies on the hypotensive effect of high potassium

5 MacGregor GA, Smith SJ, Markandu ND, Banks RA, Sagnella GA. Moderate potassium supplementation in essential hypertension. Lancet 1982;ii:567-70.

6 Meneely GR, Lemley-Stone J, Darby WJ. Changes in blood pressure and bod sodium of rats fed sodium and potassium chloride. Am f Cardiol 1961 ;8:527-32. Dahl LK, Leitl G, Heine $M$. Influence of dietary potassium and sodium potassium molar ratios on the development of salt hypertension. F Exp Med 1972;136: 
8 Louis WJ, Tabei R, Spector S. Effects of sodium intake on inherited hypertension in the rat. Lancet 1971 ;ii:1283-6.

George CF, Lewis PJ, Petrie A. Clinical experience with the use of an ultrasound sphygmomanometer. Br Heart $\mathcal{f} 1975 ; 37: 804-7$.

10 Roulston JE, MacGregor GA. Measurement of plasma renin activity by radio-

11 James VHT, Wilson GA. Determination of aldosterone in biological fluids. In: Reid E, ed. Assay of drugs and other trace compounds in biological fluids. Methodo logical development in biochemistry. Vol 5. Amsterdam: Elsevier, 1976:149-58. 12 Khaw KT, Rose G. Population study of blood pressure and associated factors in St Lucia, West Indies. Int $\mathcal{F}$ Epidemiol 1982;11:372-7.

13 Simmons D. Blood pressure, ethnic group, and salt intake in Belize. $\mathcal{f}$ Epidemiol Community Health 1983;37:38-42.

14 Smith SJ, Markandu ND, Sagnella GA, Poston L, Hilton PJ, MacGregor GA Does potassium lower blood pressure by increasing sodium excretion? A metabolic study in patients with mild to moderate essential hypertension. fournal of Hypertenston 1983;1, suppl 2:27-30.

15 Brunner HR, Baer LB, Sealey JE, Ledingham JGG, Laragh JH. The influence of potassium administration and of potassium deprivation on plasma renin in normal and hypertensive subjects. F Clin Invest $1970 ; \mathbf{4 9} \cdot 2128-38$.

16 Beard TC, Cooke HM. Gray WR, Barge R. Randomised controlled trial of no-added-sodium diet for mild hypertension. Lancet 1982; ii :455-8.
17 Erwtemant $M$, Nagelkerke N, Lubsen J, Koster M, Dunning AJ. $\beta$ Blockade, diuretics, and salt restriction for the management of mild hypertension: randomised double blind trial. Br Med $\mathcal{f} 1984 ; 289: 406-9$.

18 Watt GCM, Edwards C, Hart JT, Hart M, Walton P, Roy CJW. Dietary sodium restriction of mild hypertension in general practice. $\mathrm{Br}$ Med $\mathcal{F}$ 1983;286:432-6. 19 Richards AM, Nicholls MG, Espirer EA, et al. Blood pressure response to moderate sodium restriction and to potassium supplementation in mild essential hypertension. Lancet $1984 ; \mathrm{i}: 757-61$.

20 Smith SJ, Roberts RM, Markandu ND, MacGregor GA. Potassium: the kitchen revisited. Lancet $1983 ; \mathrm{i}: 362-3$.

21 Kurtz TW, Morris RC. Dietary chloride as a determinant of "sodium-dependent" hypertension. Science $1983 ; 222: 1139-41$

to 23 Rouse IL, Beilin LJ, Armstrong BK, Vandon. F Lab Clin Med 1982;100:261-8. effect of a vegetarian diet: controlled trial in normotensive subjects. Lancet $1983 ; \mathrm{i}: 5-10$

24 Puska P, Iacono JM, Nissinen A, et al. Controlled, randomised trial of the effect of dietary fat on blood pressure. Lancet $1983 ; 1: 1-5$.

(Accepted 12 October 1984)

\section{SHORT REPORTS}

\section{Water intoxication and oxytocin}

To reduce the time needed for induced abortions some workers have suggested using intravenous oxytocin in $5^{\circ}$, dextrose in addition to extra-amniotic prostaglandin $\mathrm{E}_{2 .}{ }^{1}$ This technique is popular and regarded as safe. I report on two patients who developed water intoxication during mid-trimester therapeutic abortions.

\section{Case reports}

CASE 1

A 31 year old woman (gravida 6, para 4) was admitted for therapeutic abortion in the 15 th week of pregnancy. She was a healthy married white woman who had had one of her previous pregnancies terminated in the 12th week of gestation without complications. On admission clinical examination, full blood count, and estimation of serum electrolyte concentrations were carried out; the results were normal. At midday on the day of admission extra-amniotic instillation of $200 \mu \mathrm{g}$ Dinoprostone (prostaglandin $E_{2}$ ) by syringe pump two hourly and intravenous oxytocin 32 IU in $5^{\circ}$ dextrose solution by IVAC pump were started. After 35 hours she became restless and confused and had a grand mal convulsion. On examination her pupils were widely dilated and unresponsive to light. Tendon reflexes were uniformly brisk and plantar responses extensor. After vaginal examination the Foley catheter and some products of conception were extracted from the introitus.

Diazepam $10 \mathrm{mg}$ intravenously and oxygen $4-6 \mathrm{l} / \mathrm{min}$ via $\mathrm{MC}$ mask were given. The intravenous oxytocin in $5^{\circ}$, dextrose infusion was stopped. Total fluid intake was 2.5 litres with $80 \mathrm{IU}$ oxytocin, and fluid output was two litres urine and $100 \mathrm{ml}$ vomit. Serum sodium concentration was $115 \mathrm{mmol}(\mathrm{mEq}) / 1$, urea $3.0 \mathrm{mmol} / 1(18 \mathrm{mg} / 100 \mathrm{ml})$, potassium 3.3 $\mathrm{mmol}(\mathrm{mEq}) / 1$, haemoglobin $13 \cdot 4 \mathrm{~g} / \mathrm{dl}$, and packed cell volume $0 \cdot 27$. After two hours of treatment with intravenous $1.8 \%$ saline, intramuscular frusemide $60 \mathrm{mg}$, and methylprednisolone $1 \mathrm{~g}$ she had a second seizure. Her condition remained critical until she regained consciousness after 42 hours of intensive care.

CASE 2

A 23 year old woman (gravida 2, para 1) was in the 14th week of pregnancy when a therapeutic abortion was carried out. There was no relevant medical or obstetric history. Physical and pelvic examinations were normal. Body weight was $53 \mathrm{~kg}$

On the day of her admission to hospital extra-amniotic prostaglandin $E_{2}$ instillation and intravenous oxytocin infusion were started. After 22 hour she developed uterine colic, for which intramuscular pethidine hydrochloride $150 \mathrm{mg}$ was given. An hour later she had a grand mal fit and aborted. Physical examination showed widely dilated pupils that responded sluggishly to light. Tendon reflexes were brisk and plantar responses extensor. There was no papilloedema. Blood pressure was $90 / 60 \mathrm{~mm} \mathrm{Hg}$ and the pulse rate $72 / \mathrm{min}$ Because of central cyanosis oxygen $41 / \mathrm{min}$ was administered via MC mask. Diazepam $20 \mathrm{mg}$ and frusemide $40 \mathrm{mg}$ were given by intramuscular injections. The intravenous oxytocin in 5\% dextrose was stopped. Total fluid intake was 2.7 litres with $93 \mathrm{IU}$ oxytocin. The urinary output was 2.02 litres. Serum sodium concentration was $121 \mathrm{mmol} / \mathrm{l}$, potassium $2.6 \mathrm{mmol} / \mathrm{l}$, urea 2.8 $\mathrm{mmol} / 1(16.8 \mathrm{mg} / 100 \mathrm{ml})$, haemoglobin $13.7 \mathrm{~g} / \mathrm{dl}$, and packed cell volume $0 \cdot 40$. Intravenous $1.8 \%$ saline at $75 \mathrm{ml} / \mathrm{h}$ was given. After 12 hours of intensive care she regained consciousness and electrolyte concentrations returned to normal.

\section{Comment}

Water intoxication in gynaecological practice is rare. Non-specific symptoms such as headache, vomiting, and restlessness preceding convulsions may often be overlooked. Biochemically, hyponatraemia occurs with serum sodium concentrations below $120 \mathrm{mmol} / 1$. Although the aetiology of the condition is still not clear, it has been attributed to haemodilution due to an overload of water containing $5 \%$ dextrose. In some cases, however, the hyponatraemia cannot be explained on the basis of dilution factor alone.

Some workers have postulated other mechanisms such as the antidiuretic effect of infusion of oxytocin ${ }^{2}$ and pethidine and morphine. ${ }^{3}$ I suggest that the use of $5^{\circ}$ dextrose in water as a vehicle for oxytocin should be abandoned and that automatic infusion systems should be used to keep infused fluid to a minimum volume.

I thank Mr J Hamlett and $\mathrm{Mr}$ A Williams for permission to publish details of their patients, and Dr R S Ramaiah for his help.

1 Embrey MP, Hillier $\mathrm{K}$, Mahendran $\mathrm{P}$. Induction of abortion by extra-amniotic prostaglandin $\mathrm{E}_{2}$ and $\mathrm{F}_{2} x . \mathrm{Br}$ Med $\mathcal{F} 1972 ;$;ii : $146-9$

dul-Karim RW, Ritzk PT. The effect of oxytocin on renal hemodynamics, water and electrolyte excretion

wgins GC. Anti-diuretic effect of oxytocin, morphine and pethidine in pregnancy and labour. Aust NZ $\mathcal{F}$ Obstet Gynaecol 1963;3:81-3.

(Accepted 8 October 1984)

Wrexham District General Hospital, Wrexham, Clwyd LL13 7TD F TOM MWAMBINGU, MRCOG, DCH, registrar in obstetrics and gynaecology Correspondence to: Department of Obstetrics and Gynaecology, King Saud University, PO Box 7805, Riyadh, Kingdom of Saudi Arabia.

\section{Fatal multisystemic toxicity associated with prophylaxis with pyrimethamine and sulfadoxine (Fansidar)}

Prophylaxis for malaria is fraught with difficulty, although recent reviews have attempted to clarify indications and drug regimens. ${ }^{12}$ We describe a healthy woman who developed a fatal multisystemic illness after taking pyrimethamine and sulfadoxine (Fansidar).

\section{Case report}

A 60 year old woman with no history of allergy was prescribed Fansidar one tablet and chloroquine sulphate $400 \mathrm{mg}$ weekly one week before leaving for a tour of Bangkok, Singapore, and Hong Kong. One week after departure she developed a fever with non-bloody diarrhoea and vomiting. In Singapore she was treated with intravenous fluids for dehydration and gastroenteritis. In Hong Kong she developed jaundice with urobilinogenuria, having taken 